Ann. Biol. anim. Bioch. Biophys., 1978, 18 (6), 1309-1315.

\title{
Advances in a method for gas analysis in metabolic experiments. Improved calibration of a Noyons diaferometer.
}

\author{
par R. GEERS, H. MICHELS *, E. DECUYPERE ** \\ Laboratorium voor Eco-Fysiologie der Huisdieren, Fakulteit der Landbouwwetenschappen, \\ Katholieke Universiteit te Leuven, Kardinaal Mercierlaan, 92, B-3030 Heverlee, Belgium.
}

Summary. The aim of this paper was to develop an improved calibration method for the gas analysis technique used by Romijn and Lokhorst $(1959,1966)$. The method consisted of a parallel analysis of respiration air at $25^{\circ} \mathrm{C}$ by a chemical absorption method on a Lloyd's gas analysis apparatus and by a physical method based on the thermal conductivity of respiratory gases, using a Noyons diaferometer (Kipp), the apparatus we wished to calibrate. Physical measurements were made at room temperatures of $25^{\circ} \mathrm{C}, 28^{\circ} \mathrm{C}$ and $31^{\circ} \mathrm{C}$.

Constant calibration coefficients could not be found by simple and multiple regression equations expressing data obtained by chemical analysis of $\mathrm{CO}_{2}$-surplus $\left(\Delta \mathrm{CO}_{2}\right.$ p. 100$)$ and $\mathrm{O}_{2}$-deficit $\left(\Delta \mathrm{O}_{2}\right.$ p. 100) as a function of the deflections on each of the two diaferometers used. Multiple regression equations expressing $\Delta \mathrm{CO}_{2}$ p. 100 and $\Delta \mathrm{O}_{2}$ p. 100 , each as a function of both deflections (d) on the $\mathrm{CO}_{2}$ - and on the $\mathrm{O}_{2}$-diaferometer, are shown in table 1c. These equations proved to fit best the corresponding chemical analysis and were used for calculation of $\Delta \mathrm{CO}_{2}$ p. 100 and $\Delta \mathrm{O}_{2}$ p. 100 in the experimental conditions described.

Simple regression equations between physical measurements at different room temperatures indicated the possibilities and the problems of transformation of data from one room temperature to another.

\section{Introduction.}

The importance of precise measurement of gas exchange in metabolic experiments has been reported by many authors at several international meetings on energy metabolism. Charlet-Lery (1958), Wöhlbier and Schneider (1961) discussed the precision of physical methods in comparison with chemical gas analysis.

In two communications Romijn and Lokhorst $(1959,1966)$ gave a delailed description of a method for the measurement of $\mathrm{O}_{2}$ - and $\mathrm{CO}_{2}$-exchanges with Wheatstone bridges in a diaferometer based on the thermal conductivity of respiratory gases.

The non-specificity of the method (Visser, 1960), taking into account metabolic components under different physiological conditions, raised problems concerning the

* Correspondence to Prof. Dr. H. Michels.

** Supported by the Belgian « Nationaal Fonds voor Wetenschappelijk Onderzoek » (N.F.W.O.). 
validity of a constant calibration coefficient pro unit $\mathrm{O}_{2}$-deficit and $\mathrm{CO}_{2}$-surplus in expired air as assumed by Romijn and Lokhorst (1966) and Ten Hoor et al. (1974). Furthermore questions arose with respect to knowledge of the thermal conductivity coefficient (Noyons, 1940).

We applied the same method, but we wanted to examine the linearity of deflections on the recording apparatus of the diaferometer resulting from varying $\mathrm{O}_{2}$-deficit and $\mathrm{CO}_{2}$-surplus in the respiration air and at different room temperatures.

\section{Materials and methods.}

Each of the two diaferometers used was calibrated by comparing the results obtained by chemical absorption of $\mathrm{CO}_{2}$ and $\mathrm{O}_{2}$ and by physical measurement with the diaferometer.

We used air originating from a respiration chamber with adjustable ventilation rate (Michels ef al., 1974) in which a hen was kept in varying conditions, i. e. feeding

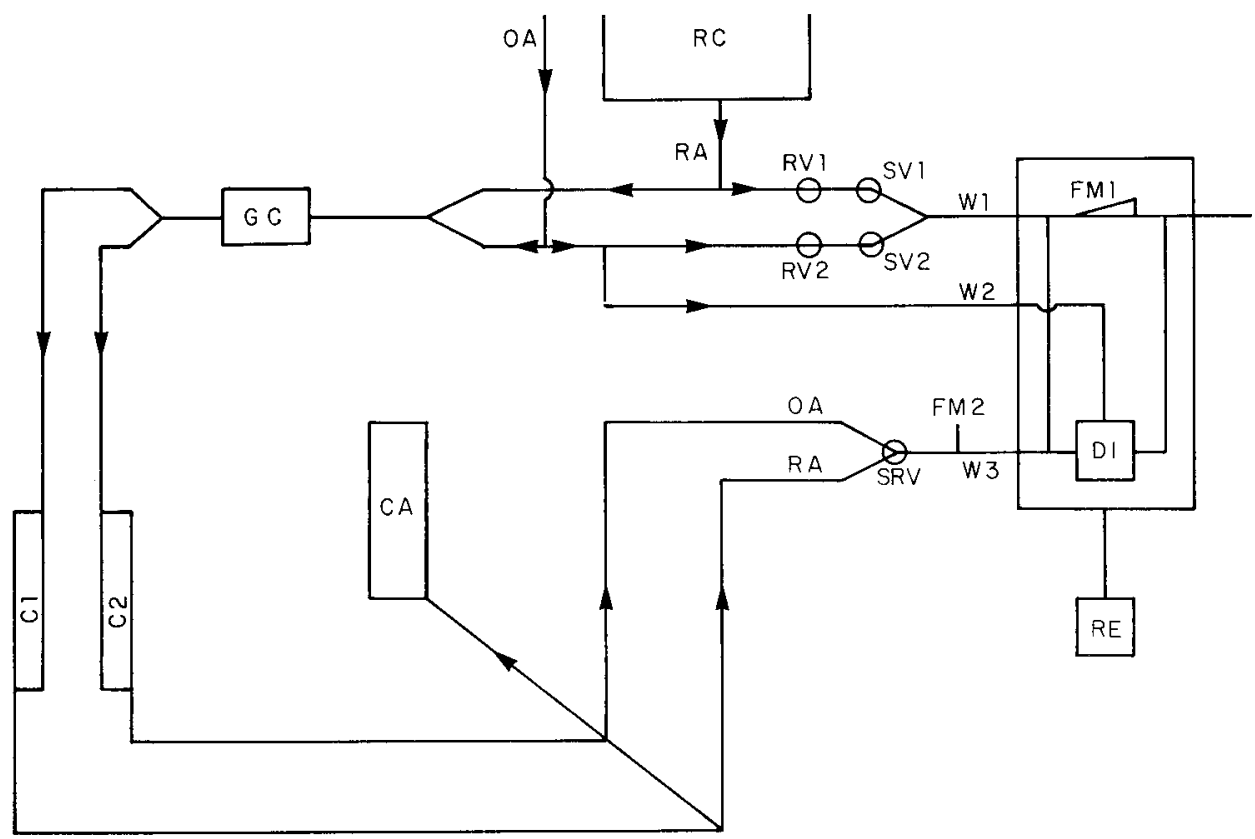

FIG. 1. - Gas supply to the diaferometer and chemical analysis during calibration.

Outdoor air (OA) coming from the cylinders (way 3) was held at a controlled rate (as well as respiration air RA) by a switching and regulating valve (SRV) in order to obtain the same base line on the recorder (RE), with way 2 (OA) taken as a reference, as when it came by way 1 (outdoor air coming either from outside or by the respiration chamber (RC). Therefore chemical (CA) and physical analysis of respiration air and outdoor air both coming from cylinders (C), and used for the calibration of each of the two diaferometers (DI), could be performed in the same conditions as during metabolic experiments. RV : regulating valve; SV : switching valve and GC : gas collecting micropump. For further explanations see text. 
and fasting, corresponding to our long-term metabolic experiments. During $6 \mathrm{hrs}$ about 4 litres of respiration air were collected by a micropump in a cylinder (Volumeter flow-rate calibrator, model 1057 Brooks) (Romijn and Vreugdenhil, 1969 ; Kampen, 1973) to perform a calibration experiment. A second cylinder of the same type was filled with outside air. The chemical analysis was made on a Lloyd gasanalysis apparatus which was adapted with a buret of $10 \mathrm{cc}$ graduated at $0.001 \mathrm{cc}$. We followed the procedure described by van Es (1958) and adapted to the apparatus (Lloyd, 1958). The mean value of three successive analyses was taken for calibration. In agreement with the literature (Weast, 1972), the outside air contained $0.03 \pm 0.009$ p. $100 \mathrm{CO}_{2}(n=15)$ and $20.942 \pm 0.0162 O_{2}(n=16)$.

For physical analysis we used two Noyons diaferometers (Kipp), each consisting of a $\mathrm{CO}_{2}$ - and $\mathrm{O}_{2}$-measuring Wheatstone bridge (Romijn and Lokhorst, 1959, 1966). Potential differences were recorded as deflections ( 1 deflection $=2 \mathrm{~mm}$ ) on a micrograph with channel selector (Kipp). Both diaferometers were thermally isolated in the same room at $25 \pm 1^{\circ} \mathrm{C}$. Physical measurements were also made at $28^{\circ} \mathrm{C}$ and $31^{\circ} \mathrm{C}$ room temperature.

The $\mathrm{CO}_{2}$-surplus $\left(\Delta \mathrm{CO}_{2}\right.$ p. 100) of respiration air was measured by comparing dried respiration air with dried outside air on one bridge, the $\mathrm{O}_{2}$-deficit $\left(\Delta \mathrm{O}_{2}\right.$ P. 100) was measured by comparing $\mathrm{CO}_{2}$-free and dried respiration air with $\mathrm{CO}_{2}$-free and dried outside air on the other bridge. The sensitivity of the latter measurement on the recorder was set at ten times the former (Romijn and Lokhorst, 1959, 1966).

Physical conditions during our metabolic experiments and during the calibration were identical, as shown in figure 1 and in the steps described below. The main point is that outside air coming from the cylinder (way 3 with way 2 taken as a reference) was put through the measuring channels at a controlled flow rate (FM $1 / 2$ : flow meters 1 and 2) in order to obtain the same base line on the recorder as when supplying outside air in metabolic conditions (way 1 versus way 2). The base line was always determined by comparing outside air with outside air.

To check the composition of outside air several air samples were taken directly from outside and from different places in the tubes connected with the respiration chamber. The air-tightness of the whole installation was further proved by the recovery of a known amount of $\mathrm{CO}_{2}$ (van Es, 1961).

Calibration was carried out as follows :

1. Chemical gas analysis of outside air (O.A.) and respiration air (R.A.).

2. Determination of the base line with outside air (O.A.) from Way 1 (W1) and Way 2 (W2 - fixed reference supply).

3. Control of the base line by supplying outside air (O.A.) from cylinder 2 (Way 3 : W3) at a controlled flow rate (air supply from way 2 fixed).

4. Supply of respiration air (R.A.) from cylinder 1 (Way 3) at the same flow rate as from cylinder 2 (see step 3). Reading of deflections $\left(\mathrm{d} \mathrm{O}_{2}, d \mathrm{CO}_{2}\right)$ on the micrographrecorder (RE).

5. Renewed control of the base line (see step 2).

6. Renewed chemical gas analysis (see step 1). 


\section{Results and discussion.}

Recorder deflections of both diaferometers varied between 10.5 and 30.7 (diaferometer 1), and between 11.3 and 33.6 (diaferometer 2), corresponding to values for $\Delta \mathrm{CO}_{2}$ (in p. 100) between 0.1097 and 0.3625 obtained from chemical analysis. With respect to oxygen deficit deflections varied between 14.5 and 29.4 (diaferometer 1 ), and between 14.0 and 33.0 (diaferometer 2), corresponding to values for $\Delta \mathrm{O}_{2}$ (in p. 100) between 0.1628 and 0.4325 from chemical analysis.

Relationships between data were made by means of regression analyses based on the theoretical model of the linear regression equation : $Y=\beta X+\alpha+\varepsilon$ (Wonnacott and Wonnacott, 1972). The parameters « $a$ » (constant) and « $b$ » (regression coefficient) were the best estimated of $\alpha$ and $\beta$, the random error being 0 .

Simple regression equations and correlation coefficients at $25^{\circ} \mathrm{C}$ between data from chemical analysis $(Y)$ and corresponding deflections $(X)$ are given in table $1 a$. The significance of the statistical parameters was not tested here or in the following regression equations because of random distribution problems (Wonnacott and Wonnacott, 1972). The regression equations showed the linearity of the physical process as a whole, but a constant calibration coefficient could not be proved because of the presence of a relatively important value for constant «a».

\section{TABLE 1}

Regression equations and correlation coefficients ( $r$ ) between $\Delta \mathrm{CO}_{2}$ and $\Delta \mathrm{O}_{2}$ in p. 100 , measured by chemical analysis and deflections (d) on the diaferometer.

$\mathrm{D} 1=$ diaferometer $1 ; \mathrm{D}_{2}==$ diaferometer 2
a) D1 $\triangle \mathrm{CO}_{2}$ p. $100=0.0123 \mathrm{~d} \mathrm{CO}_{2}-0.0143 \quad \mathrm{r}==0.9885$
D1 $\Delta \mathrm{O}_{2}$ p. $100=0.0153 \mathrm{~d} \mathrm{O}-0.032 \quad r=0.9715$
D2 $\triangle \mathrm{CO}_{2}$ p. $100=0.0117 \mathrm{~d} \mathrm{CO}_{2}-0.0006 \quad \mathrm{r}=0.9837$
D2 $\Delta \mathrm{O}_{2}$ P. $100=0.0124 \mathrm{~d} \mathrm{O}_{2}-0.0041 \quad r=0.9568$
b) $\mathrm{D} 1 \mathrm{~d} \mathrm{CO}_{2}=58.34 \Delta \mathrm{CO}_{2}$ p. $100+20.31 \Delta \mathrm{O}_{2}$ p. $100+0.74 \mathrm{r}=0.9927$
D1 $\mathrm{d} \mathrm{O}_{2}=8.01 \Delta \mathrm{CO}_{2}$ P. $100+55.75 \Delta \mathrm{O}_{2}$ P. $100+2.83 \quad r=0.9726$
D2 $\mathrm{d} \mathrm{CO}_{2}=52.47 \Delta \mathrm{CO}_{2}$ p. $100 \dashv 33.18 \Delta \mathrm{O}_{2}$ p. $100-0.02 \quad \mathrm{r}=0.9918$
D2 $\mathrm{d} \mathrm{O}_{2}=-20.96 \Delta \mathrm{CO}_{2}$ p. $100+91.96 \Delta \mathrm{O}_{2}$ p. $100+1.46 \mathrm{r}=0.9590$
c) D1 $\triangle \mathrm{CO}_{2}$ p. $100=0.0108 \mathrm{~d} \mathrm{CO}_{2}+0.0015$ d $\mathrm{O}_{2}-0.1290 \quad r=0.9866$

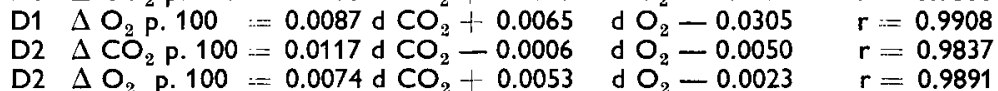

The reasons for these relatively high « a »-values were investigated by expressing each of the two deflections $(d=Y)$, respectively, on the $\mathrm{CO}_{2}$ - and on the $\mathrm{O}_{2}$-measuring channels as a function of $\mathrm{CO}_{2}$-surplus $\left(\Delta \mathrm{CO}_{2}\right.$ p. $\left.100=\mathrm{X}_{1}\right)$ and $\mathrm{O}_{2}$-deficit $\left(\Delta \mathrm{O}_{2}\right.$ p. $\left.100=X_{2}\right)$, measured by chemical analysis using a multiple regression equation : $y=b_{1} X_{1}+b_{2} X_{2}+a$ (Wonnacott and Wonnacott, 1972). These results are given in table $1 b$ and prove, by the magnitude of partial b-coefficients, that both gas exchanges $\left(\Delta \mathrm{CO}_{2}\right.$ p. 100 and $\Delta \mathrm{O}_{2}$ p. 100) can be measured on each of the channels. However, relatively important « a »-values (at least with respect to $\mathrm{O}_{2}$-measurements) 
again showed that a constant calibration coefficient could not be proved. This suggests the hypothesis of interacting effects from quantitatively varying gas components, contributing to the thermal conductivity of gas mixtures taken as a whole. In this case attention should be drawn to the possible effect of chemical $\mathrm{CO}_{2}$ absorption before the physical analysis of $\mathrm{O}_{2}$-deficit was made.

Moreover, because of the differential magnitude of partial b-coefficients in each of the preceding equations, the hypothesis was proposed that $\Delta \mathrm{CO}_{2}$ and $\Delta \mathrm{O}_{2}$ (both in p. 100 , obtained by chemical analysis) could be more precisely approximated by taking into account the deflections on the $\mathrm{O}_{2}$ - and $\mathrm{CO}_{2}$-measuring channels. Therefore, multiple regression equations were calculated and are given in table $1 c$. Differences between values obtained from these regressions and from chemical analyses were $0.0095 \pm 0.0093$ p. $100 \mathrm{CO}_{2}$ and $0.010 \pm 0.0085$ p. $100 \mathrm{O}_{2}$ on diaferometer 1 and $0.0116 \pm 0.0111$ p. $100 \mathrm{CO}_{2}$ and $0.0114 \pm 0.0086$ p. $100 \mathrm{O}_{2}$ on diaferometer 2 These differences were on the average $50 \mathrm{p}$. 100 lower, especially for $\mathrm{O}_{2}$, than when simple regression equations were used for this comparison. Taking into account that most of the deflections on the recorders of both diaferometers were between 20 and 30 , we still had an average relative error of about 3 p. 100 between chemical and physical analyses. There is probably about a 1 p. 100 error when calibrating at $\mathrm{O}_{2}$-deficits and $\mathrm{CO}_{2}$-surpluses between 0.5 and 1.0 p. 100 , assuming similar mathematical relationships on the total range.

To investigate the relationship between physical measurements at different room temperatures, we expressed the values obtained at $25^{\circ} \mathrm{C}$ as a function of their corresponding values at $28^{\circ} \mathrm{C}$ or $31^{\circ} \mathrm{C}$. As can be seen from table 2 , simple regression equations again had typical « $a$ » and «b » values, nothwithstanding the fact that each $y$ and $x$ couple belonged to the same air sample, the different air samples once more covering the range of respiration air samples in our experimental conditions, as mentioned above. In the case of $\mathrm{O}_{2}$ especially, we found a non-negligible " a value » (higher than the resolution of the recorder), again indicating interacting effects when transforming data from one temperature to another. Moreover, taking into accountdifferent $« b$ » values for each environmental temperature (regression lines $25 / 28^{\circ} \mathrm{C}$ and $25 / 31^{\circ} \mathrm{C}$ were not parallel) these interacting effects depended on the environmental temperature at which we made our measurements. A temperature effect was also observed by Visser (1960).

\section{TABLE 2}

Simple regression equations and correlation coefficients between deflections at $25^{\circ} \mathrm{C}(\mathrm{Y})$ and corresponding deflection values af $28^{\circ} \mathrm{C}$ or $31^{\circ} \mathrm{C}(\mathrm{X})$

$\mathrm{D} 1=$ diaferometer $1 ; \mathrm{D} 2=$ diaferometer 2

\begin{tabular}{llllll}
\hline D1 & $25 / 28$ & $C O_{2}$ & $Y=0.9971 \times+0.2285$ & $\mathbf{r}=0.9994$ \\
& $25 / 31$ & $C O_{2}$ & $Y=1.0235 X+0.1570$ & $r=0.9994$ \\
& $25 / 28$ & $O_{2}$ & $Y=1.0330 X-2.6337$ & $r=0.9779$ \\
& $25 / 31$ & $O_{2}$ & $Y=0.9663 \times-1.7625$ & $r=0.9929$ \\
& $25 / 28$ & $C O_{2}$ & $Y=1.0260 \times-0.3841$ & $r=0.9983$ \\
& 25131 & $C O_{2}$ & $Y=1.0387 \times-0.4298$ & $r=0.9975$ \\
& $25 / 28$ & $O_{2}$ & $Y=0.9615 \times-0.8336$ & $r=0.9851$ \\
& $25 / 31$ & $O_{2}$ & $Y=0.9387 \times-0.7693$ & $r=0.9969$ \\
\hline
\end{tabular}




\section{Conclusions.}

1. On the basis of the calibration procedure used and the calculations of data, we could not find a constant calibration coefficient within the measuring range of varying $\mathrm{O}_{2}-$ deficits and $\mathrm{CO}_{2}$-surpluses at three environmental temperatures.

2. The relationships between chemical and physical measurements were most precisely expressed mathematically by means of multiple linear regression equations. These linear relationships did prove to be a more accurate physical method for using the diaferometer, especially in continuous metabolic experiments.

3. Data measured at different environmental temperatures could be transformed to comparable results at the same room temperature.

4. The problems of possible interacting effects of varying gas components in the thermal conductivity of respiration air should be examined in systematic investigations within and between environmental temperafures.

Reçu en avril 1978.

Accepté en juin 1978.

Résumé. Dans les recherches présentées nous avons voulu perfectionner la méthode d'étalonnage utilisée par Romijn et Lokhorst $(1959,1966)$ afin de déterminer le déficit d'oxygène et le surplus d'anhydride de carbone dans l'air expiré par les animaux soumis à l'expérience. La méthode comprenait deux analyses parallèles à une fempérature environnante de $25^{\circ} \mathrm{C}$, l'une par absorption chimique des gaz dans un appareil de Lloyd, l'autre dans un diaféromètre à étalonner, cette méthode étant basée sur la conductibilité thermique des gaz. Nous avons également effectué ces analyses parallèles à deux autres températures environnantes : $28^{\circ} \mathrm{C}$ et $31^{\circ} \mathrm{C}$.

Nous n'avons pas été en mesure de trouver des coefficients d'étalonnage consiants, ni pour le déficit d'oxygène $\left(\Delta \mathrm{O}_{2}\right.$ p. 100) ni pour le surplus d'anhydride de carbone $\left(\Delta \mathrm{CO}_{2}\right.$ p. 100), en exprimant les résultats obtenus par analyse chimique dans des équations de régression simples ou multiples en fonction des déflections observées sur chacun des deux diaféromètres. Des équations de régression multiples exprimant $\Delta \mathrm{CO}_{2} \mathrm{p} .100$ et $\Delta \mathrm{O}_{2}$ p. 100 en fonction des deux déflections, c.-à.-d. pour l'oxygène et pour l'anhydride de carbone figurent dans le tableau $1 c$ et s'approchaient le plus des résultats des analyses chimiques.

Il était également possible de tenir compte de l'influence de la température ambiante à l'aide d'équations de régression simples (tabl. 2).

\section{References}

CHARLET-LERY G., 1958. Précisions analytiques obtenus avec certains appareils de dosages physiques (Beckmann-O $\mathrm{O}_{2}$, Analyseur infrarouge- $\mathrm{CO}_{2}$ ). Proc. Ist Symp., Energy Metab., Copenhagen. EAAP. Publ. no 8, 124-137.

KAMPEN M. V., 1973. Energiemetabolisme en warmferegulatie van de Wifte Leghorn hen. Proefschrift, Utrecht.

LLOYD B. B., 1958. A development of Haldane's gasanalysis apparafus. J. Physiol., 143, 5-6P.

MICHELS H., GEERS R., MUAMBI S., 1974. The effect of incubation temperature on pre- and posthatching development in chickens. Br. Poultr. Sci., 15, 517-523.

NOYONS A. K. M., 1940. Méthode d'enregistrement continu de la teneur en $\mathrm{CO}_{2}$ et en $\mathrm{O}_{2}$ des gaz respiratoires au moyen du diaféromètre thermique, servant à l'étude du métabolisme des tissus des animaux et de l'homme. Ann. Physiol. Physicochim. biol., 3, 909-934. 
ROMIJN C., LOKHORST W., 1959. Improved gas analysis in metabolic experiments. Acta physiol. pharmacol. neerl., 8, 137-151.

ROMIJN C., LOKHORST W., 1966. Improved gas analysis in metabolic experiments. Second communication. Acta physiol. pharmacol. neerl., 14, 1-11.

ROMIJN C., VREUGDENHIL. E. L., 1969. Energy balance and heat regulation in the White Leghorn fowl. Neth. J. vet. Sci., 2, 32-58.

TEN HOOR F., RISPENS P., VAN DE WALL E., ZIJLSTRA W. G., 1974. Defermination of oxygen uptake and carbon dioxide production in animals and man using a diaferometer calibrated with expired gas. Application in the direct Fick procedure for determining cardiac output. Proc. Koninkl. Nederl. Akad. Wetensh., C, 77, 429-452.

VAN ES A. J. H., 1958. Gas analysis in open circuit respiration chambers. Proc. Ist Symp., Energy Melab., Copenhagen, EAAP Publ. no 8, 132-137.

VAN ES A. J. H., 1961. Between animal variation in the amount of energy required for the maintenance of cows. Pudoc, Wageningen.

VISSER B. F., 1960. Clinical gas analysis based on thermal conductivity. Thesis, Utrecht.

WEAST R. C., 1972. Handbook of Chemistry and Physics. C. R. C., Cleveland Ohio.

WÖHLBIER W., SCHNEIDER W., 1961. Die Bestimmung des Sauerstoffgehalts von Gasen mit Hilfe eines physikalischen Messgerätes. Proc. 2nd Symp., Energy Metab., Wageningen. EAAP Publ. no 10, 32-39.

WONNACOTT T. H., WONNACOTT R. J., 1972. Introductory Statistics. Wiley, New York. 